\title{
Investigation of a Q Fever Outbreak in a Scottish Co-Located Slaughterhouse and Cutting Plant
}

\author{
L. E. Wilson ${ }^{1}$, S. Couper², H. Prempeh², D. Young ${ }^{3}$, K. G. J. Pollock ${ }^{1}$, W. C. Stewart ${ }^{1,4}$, \\ L. M. Browning ${ }^{1}$ and M. Donaghy ${ }^{1}$ \\ ${ }^{1}$ Health Protection Scotland, Clifton House, Clifton Place, Glasgow, Scotland \\ 2 Public Health Department, NHS Forth Valley, Carseview House, Castle Business Park, Stirling, Scotland \\ ${ }^{3}$ Department of Statistics and Modelling Science, University of Strathclyde, Livingstone Tower, Glasgow, Scotland \\ ${ }^{4}$ Animal Health, Station Street, Stranraer, Scotland
}

Impacts
- This paper reports on the largest outbreak of Q fever that has ever occurred
in Scotland with 110 cases.
- The outbreak occurred in a co located slaughterhouse and cutting plant
and highlights the significance of taking into consideration the full range of
work related activities occurring in occupational outbreaks.
- Epidemiological investigation supported the hypothesis of the sheep lairage
being the potential source of exposure to the infective agent.

Keywords:

Q fever; Coxiella burnetii; slaughterhouse; migrant workers

\section{Correspondence:}

L. E. Wilson. Respiratory Section, Health Protection Scotland, Clifton House, Clifton Place, Glasgow G3 7LN, Scotland.

Tel.: 0141300 1100; Fax: 0141300 1170;

E mail: louise.wilson2@nhs.net

\begin{abstract}
Summary
Outbreaks of Q fever are rare in the UK. In 2006, the largest outbreak of Q fever in Scotland occurred at a co located slaughterhouse and cutting plant with 110 cases. Preliminary investigations pointed to the sheep lairage being the potential source of exposure to the infective agent. A retrospective cohort study was carried out among workers along with environmental sampling to guide public health interventions. A total of 179 individuals were interviewed of whom $66(37 \%)$ were migrant workers. Seventy five (41.9\%) were serologi cally confirmed cases. Passing through a walkway situated next to the sheep lairage, a nearby stores area, and being male were independently associated with being serologically positive for $\mathrm{Q}$ fever. The large proportion of migrant workers infected presented a significant logistical problem during outbreak investigation and follow up. The topic of vaccination against $Q$ fever for slaughterhouse workers is contentious out with Australasia, but this outbreak highlights important occupational health issues.
\end{abstract}

\section{Introduction}

Q fever is a zoonosis caused by the obligate intracellular bacterium, Coxiella burnetii. The disease was first recog nized by Edward Holbrook Derrick who investigated an outbreak of 'abattoir fever' in employees of a meatpacking plant in Australia (Derrick, 1937). The reservoir of the organism is extensive, including a wide range of ungulates and the ticks that parasitise them. Organisms are shed in the urine, faeces, milk and parturition products of infected animals (Maurin and Raoult, 1999). Coxiella bur netii can exist as a highly resistant spore like form, which may survive for many months before causing infection. The infective dose of the organism is believed to be very low, and large outbreaks can arise from small sources. Humans most often become infected by inhalation of contaminated aerosols (Van Woerden et al., 2004).

Acute $\mathrm{Q}$ fever presents with a range of symptoms, including fever, respiratory illness and hepatitis (Maurin and Raoult, 1999). Asymptomatic infection, diagnosed through serology, is also well recognized. Immuno compromised individuals or those with cardiac valve abnormalities are at increased risk of developing chronic Q fever (Fenollar et al., 2001). Chronic disease can occur 
years after initial infection, with endocarditis a common presentation (Maurin and Raoult, 1999). Clinical follow up and serological testing are keys to diagnosis (Raoult and Marrie, 1995).

The average number of reported cases of $\mathrm{Q}$ fever in Scotland, where Q fever is not a notifiable disease, is less than 10 per annum, with approximately 100 cases being reported in the UK (Cutler et al., 2002). Most cases in the UK are sporadic. However, a number of outbreaks have occurred, the most recent occurring in England in 2007 (Health Protection Agency, 2007). The largest out break in the UK occurred in Solihull in 1989, in which 147 cases were associated with windborne spread from farmland to an urban area (Smith et al., 1993; Hawker et al., 1998). In 2002, 95 cases of Q fever were identified in employees of a cardboard factory in South Wales. The hypothesized mode of transmission was aerosolization due to drilling of contaminated straw board during renovation work (Van Woerden et al., 2004).

We report an investigation into an outbreak of $\mathrm{Q}$ fever at a rural co located slaughterhouse and cutting plant in Scotland in the summer of 2006. At the time of the inves tigation, the plant was dealing with the slaughter, boning and despatching of approximately 1650 cattle and 5000 to 10000 sheep per week. In July 2006, a Scottish public health department received notification of respiratory and gastrointestinal symptoms in employees of a co located slaughterhouse and cutting plant. Two employees with respiratory illness had required hospitalization, so an outbreak control team was assembled to investigate and manage the incident. Organizations represented at the outbreak control meetings included Public Health from NHS Health Boards, Environmental Health, Health Pro tection Scotland, the Health and Safety Executive and the Food Standards Agency.

\section{Materials and Methods}

\section{Epidemiological investigation}

A preliminary questionnaire was designed for administra tion to the workers who were unwell to aid diagnosis of the causative organism, produce a case definition and generate a hypothesis for areas of risk in the plant. Spe cific questions on the presence of headache, fever, muscle pains, joint pains or dry cough were included, as well as others on upper and lower respiratory tract symptoms, gastrointestinal symptoms and general symptoms includ ing rash and lethargy.

At the end of July 2006, when the illness had been identified as Q fever, a more detailed hypothesis testing epidemiological investigation was carried out to calculate attack rates based on main location of work. The work force of the factory fluctuated daily and was approxi mately 200, with around 120 individuals estimated to fall into the exposed group and 80 into the non exposed group. An attack rate of $40 \%$ was estimated in the exposed group. Given an attack rate among the exposed of $40 \%$, the study would have adequate power (greater than 0.80 ) to detect a percentage reduction in the attack rate among the non exposed of $50 \%$ or greater. A con venience sample of workers present at the plant was used. A detailed questionnaire was administered face to face to 179 employees, coupled with blood sampling over 2 days at the site. Details on workers who chose not to participate were not recorded. Informed consent was obtained. The administration of the questionnaires was by health care workers and epidemiologists, with the aid of translators, as English was not the first lan guage for a number of employees. Further serological testing of antibody negative individuals was offered in September 2006 due to the long incubation period of Q fever. The outbreak control team decided that all antibody positive individuals should be offered clinical follow up.

The questionnaire explored exposure from 1st June 2006 to a range of risk factors, both work and commu nity based. Details of work activities (exposure to animals and animal products) and the main location of work and movement in and around the plant through specific areas were obtained directly through specific questions. The questionnaire also covered community based exposure to animals and animal products. Details on symptoms expe rienced (specifically the presence of fever, headache, mus cle pain, dry cough or joint pain) and dates of onset of illness were collected and an epidemic curve produced. Symptomatic illness was defined as the presence of two or more of fever, headache, dry cough, joint pain or muscle pain.

\section{Microbiological investigation}

Phase 1 and Phase $2 \operatorname{IgM}$ antibody analyses were carried out at the West of Scotland Regional Virology Labo ratory, using indirect immuno fluorescence (Focus Diagnostics; Focus Diagnostics Inc, Cypress, CA, USA).

The following case definitions were used in the epide miological investigation following national and interna tional consultation:

Confirmed case: anyone who has worked in the plant from 1st June 2006 and has, on serological testing, an IgM Phase I or Phase II immunoglobulin titre of $\geq 256$ for C. burnetii.

Probable case: anyone who has worked in the plant from 1st June 2006 and has, on serological testing, an IgM Phase I or Phase II immunoglobulin titre of $\geq 64$ but $<256$ for C. burnetii. 


\section{Statistical analyses}

Descriptive statistics were calculated and confirmed cases compared with probable and negative cases. Univariate analyses were carried out to ascertain if there was a statis tically significant association between being a 'case' and passing through particular rooms and walkways in the plant. Variables associated with an increased risk in the univariate analysis were included in logistic regression models. The modelling was performed for two scenarios, confirmed cases versus probable and negative cases (model 1) and secondly, confirmed and probable cases versus negative cases (model 2). Model 2 was included as the likelihood of a probable case with an increased IgM titre having Q fever is likely to be elevated in an outbreak situation. Data were analysed using spss 14.0 (SPSS Inc., Chicago, IL, USA) software at a significance level of $5 \%$.

\section{Environmental investigation}

Local environmental health officers and Health and Safety Executive (HSE) staff carried out environmental assess ments of the factory, starting on 11th July to determine the causative organism and detect if there was an ongoing risk. Visits were made in conjunction with the members of the Outbreak Control Team wherever appropriate. Environmental samples were collected from the boning and cattle slaughter areas, animal pens, bedding and air vents, and polymerase chain reaction (PCR) analysis for C. burnetii was performed at the Special Pathogens Refer ence laboratory, Porton Down, UK.

Air leakage tests were carried out by HSE staff to explore potential routes of infection from the cattle and sheep lai rages. Buildings were filled with glycol vapour or 'smoke' from commercial smoke generators (Colt 4). This allowed the airflow through the lairages to be visually tracked.

\section{Results}

Epidemiological and Microbiological results

Q fever was serologically confirmed by 18 th July in a hos pitalized case. An apparent higher incidence of illness in people with areas of work near the sheep lairage was noted in the preliminary questionnaire, resulting in an epidemiological null hypothesis of no association between inhalation of aerosols contaminated with fomites from the sheep lairage and testing positive for Q fever.

There were 110 cases identified overall in the outbreak. All of the 179 individuals interviewed in this study under went serological testing, and there were $75(41.9 \%)$ con firmed and $23(12.8 \%)$ probable cases. Sixty six (37\%) of interviewees were migrant workers. An epidemic curve was produced (Fig. 1), which showed a wide range of dates of

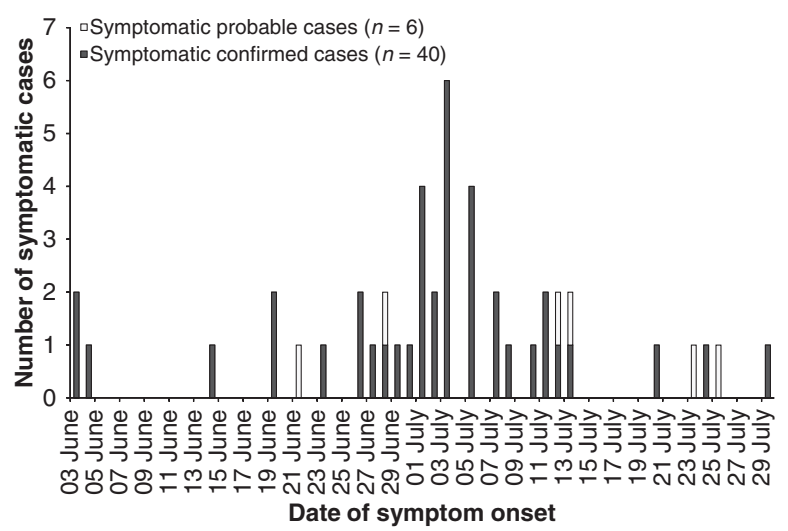

Fig. 1. Epidemic curve showing symptomatic cases and date of symptom onset.

onset of symptoms between 3rd June 2006 and 29th July 2006. In all, $97.3 \%$ of the confirmed cases were male, com pared with $83.7 \%$ of the probable and negative cases. There was no significant difference between the mean $( \pm \mathrm{SD})$ age of confirmed cases and probable/negative cases $(37.4 \pm 11.5$ versus $34.7 \pm 11.1$ respectively, $P=0.12)$. A total of $56 \%$ of cases experienced fever, $43 \%$ headache, $27 \%$ dry cough, $33 \%$ joint pain and $49 \%$ muscle pain. Forty two $(56 \%)$ of the confirmed cases experienced symp tomatic illness (as defined by two or more of fever, head ache, dry cough, joint pain or muscle pain) compared with $17(16 \%)$ of the probable and negative cases.

On univariate analysis more cases than expected were identified in those who passed the boning area, the pack ing area and the stores (Table 1). More cases than expected were identified in those who passed through walkway 2 by the sheep lairage, walkway 3, walkway 8 and walkway 9 (Table 2). Fewer cases than expected were identified in those who passed through walkway 4, walk way 5 and walkway 7 . Walkways 2, 3, 8 and 9 are in the northern half of the factory, as are the boning area, the packing area and the stores. Walkways 4, 5 and 7, the offices and the cattle slaughter line are in the southern half of the factory.

Using logistic regression, in model 1 (confirmed cases versus probable and negative cases), passing through the stores, passing through walkway 2 by the sheep lairage and being male were independently associated with an increased risk of testing positive. Those who passed although the stores were 3.2 (95\% CI: 1.7 6.3) times as likely to be a confirmed case, those who passed through walkway 2 were 2.1 (95\% CI: 1.04 .3 ) times as likely and men 5.2 (95\% CI: 1.124 .0$)$ times as likely to be a con firmed case. In model 2, confirmed and probable cases versus negative cases, passing through the stores (2.1, 95\% CI: 1.04 .0$)$, passing through walkway 2 (2.2, 95\% CI: 1.14 .2$)$ and being male $(6.4,95 \%$ CI: 1.823 .4$)$ 
Table 1. Attack rates and relative risks for individuals passing through workplace areas

\begin{tabular}{|c|c|c|c|c|c|c|c|}
\hline \multirow[b]{2}{*}{ Area } & \multirow[b]{2}{*}{ Exposure } & \multicolumn{2}{|l|}{ Case } & \multirow[b]{2}{*}{ Total } & \multirow[b]{2}{*}{ Attack rate } & \multirow[b]{2}{*}{ Relative risk } & \multirow[b]{2}{*}{$95 \% \mathrm{Cl}$} \\
\hline & & Yes & No & & & & \\
\hline \multirow{2}{*}{ Reception } & Yes & 35 & 44 & 79 & 0.443 & 1.108 & $0.785,1.563$ \\
\hline & No & 40 & 60 & 100 & & & \\
\hline \multirow[t]{2}{*}{ Sheep slaughter } & Yes & 40 & 66 & 106 & 0.377 & 0.787 & $0.559,1.108$ \\
\hline & No & 35 & 38 & 73 & & & \\
\hline \multirow[t]{2}{*}{ Meat chills } & Yes & 23 & 36 & 59 & 0.390 & 0.900 & $0.616,1.314$ \\
\hline & No & 52 & 68 & 120 & & & \\
\hline \multirow[t]{2}{*}{ Meat chills area 2} & Yes & 35 & 40 & 75 & 0.467 & 1.213 & $0.861,1.171$ \\
\hline & No & 40 & 64 & 104 & & & \\
\hline \multirow[t]{2}{*}{ Cattle slaughter } & Yes & 33 & 60 & 93 & 0.355 & 0.727 & $0.512,1.030$ \\
\hline & No & 42 & 44 & 86 & & & \\
\hline \multirow[t]{2}{*}{ Office } & Yes & 16 & 30 & 46 & 0.348 & 0.784 & $0.505,1.216$ \\
\hline & No & 59 & 74 & 133 & & & \\
\hline \multirow[t]{2}{*}{ Boning } & Yes & 54 & 56 & 110 & 0.491 & 1.669 & $1.103,2.526$ \\
\hline & No & 20 & 48 & 68 & & & \\
\hline \multirow[t]{2}{*}{ Packing } & Yes & 51 & 48 & 99 & 0.515 & 1.769 & $1.194,2.623$ \\
\hline & No & 23 & 56 & 79 & & & \\
\hline \multirow[t]{2}{*}{ Stores } & Yes & 39 & 23 & 62 & 0.629 & 2.044 & $1.466,2.850$ \\
\hline & No & 36 & 81 & 117 & & & \\
\hline
\end{tabular}

Table 2. Attack rates and relative risks for individuals passing along walkways

\begin{tabular}{|c|c|c|c|c|c|c|c|}
\hline \multirow[b]{2}{*}{ Area } & \multirow[b]{2}{*}{ Exposure } & \multicolumn{2}{|c|}{ Case } & \multirow[b]{2}{*}{ Total } & \multirow[b]{2}{*}{ Attack rate } & \multirow[b]{2}{*}{ Relative risk } & \multirow[b]{2}{*}{$95 \% \mathrm{Cl}$} \\
\hline & & Yes & No & & & & \\
\hline \multirow[t]{2}{*}{ Walkway 1} & Yes & 53 & 64 & 117 & 0.453 & 1.277 & $0.864,1.886$ \\
\hline & No & 22 & 40 & 62 & & & \\
\hline \multirow[t]{2}{*}{ Walkway 2} & Yes & 59 & 63 & 122 & 0.484 & 1.723 & $1.094,2.713$ \\
\hline & No & 16 & 41 & 57 & & & \\
\hline \multirow[t]{2}{*}{ Walkway 3} & Yes & 27 & 20 & 47 & 0.574 & 1.589 & $1.136,2.23$ \\
\hline & No & 47 & 83 & 130 & & & \\
\hline \multirow[t]{2}{*}{ Walkway 4} & Yes & 30 & 62 & 92 & 0.326 & 0.630 & $0.441,0.901$ \\
\hline & No & 45 & 42 & 87 & & & \\
\hline \multirow[t]{2}{*}{ Walkway 5} & Yes & 24 & 57 & 81 & 0.296 & 0.569 & $0.387,0.837$ \\
\hline & No & 51 & 47 & 98 & & & \\
\hline \multirow[t]{2}{*}{ Walkway 6} & Yes & 33 & 56 & 89 & 0.371 & 0.805 & $0.566,1.144$ \\
\hline & No & 41 & 48 & 89 & & & \\
\hline \multirow[t]{2}{*}{ Walkway 7} & Yes & 22 & 55 & 77 & 0.286 & 0.555 & $0.372,0.828$ \\
\hline & No & 52 & 49 & 101 & & & \\
\hline \multirow[t]{2}{*}{ Walkway 8} & Yes & 32 & 29 & 61 & 0.525 & 1.461 & $1.040,2.053$ \\
\hline & No & 42 & 75 & 117 & & & \\
\hline \multirow[t]{2}{*}{ Walkway 9} & Yes & 51 & 47 & 98 & 0.520 & 1.713 & $1.167,2.515$ \\
\hline & No & 24 & 55 & 79 & & & \\
\hline
\end{tabular}

remained independently statistically significantly associ ated with an increased risk of testing positive.

\section{Environmental results}

Polymerase chain reaction tests on all environmental sam ples were negative for C. burnetti. Smoke tests conducted under conditions reflecting the different air pressures likely to have arisen in the lairage, revealed leakage from the sheep lairage around the fire door, with substantial spread into the courtyard (which comprised walkway 2) when the fire door was left open.

\section{Discussion}

This is the largest outbreak of Q fever that has ever occurred in Scotland. Slaughterhouses are a recognized location for outbreaks of Q fever (Shapiro et al., 1990), 
given the widespread prevalence of $C$. burnetii in livestock and the low infective dose of this organism. Epidemiolog ical investigation of the outbreak provided evidence to reject the null hypothesis of no association between inha lation of aerosols contaminated with fomites from the sheep lairage and testing positive for $\mathrm{Q}$ fever. The neigh bouring area used as an access route (walkway 2) by workers was the most likely location of exposure, although this was not proven.

The proportion of individuals clinically unwell corrob orates previous reports (Raoult and Marrie, 1995; Maurin and Raoult, 1999). With $44 \%$ of confirmed cases not hav ing symptomatic illness, this study emphasizes the impor tance of serological testing for $\mathrm{Q}$ fever in individuals who may have been exposed but are clinically well. (Thomas et al., 1995).

There are a number of limitations to the epidemiologi cal analysis. Some individuals who were clinically unwell had taken part in the earlier hypothesis generating ques tionnaire, when the cause of illness in the plant was unknown. It is not known if participation in the previous questionnaire influenced participation in the second ques tionnaire. Also, when this study was carried out, inter viewing occurred at the workplace and only individuals rostered to be at work and well enough to be at work were included. It is possible that more severely symptom atic cases or cases of more recent onset were excluded by this approach, but it is difficult to predict the impact of this on models 1 and 2 .

Analysis of the epidemiological questionnaire is also complicated by the fact that the areas analysed are not independent in so far as the geographical layout of the plant determines which areas an individual passes through. Individuals entering from the 'sheep' entrance are likely to remain in the sheep processing section of the plant and the cutting areas, and those entering from the 'cattle' entrance are likely to remain in the cattle processing section of the plant apart from the cutting areas. Superimposed on this structural restriction is the patterning of movement relating to work hygiene regula tions, with areas of the factory designated as 'clean' and 'dirty'.

The potential burden of $\mathrm{Q}$ fever on the health of the cases is considerable. Chronic Q fever is estimated to occur in around 5\% of cases (Raoult and Marrie, 1995), and there are reports of prolonged fatigue syndrome fol lowing infection with Q fever (Wildman et al., 2002). Q fever can pose specific health risks for pregnant women (Raoult et al., 2002). The burden on the health care ser vices following the outbreak was considerable, with spe cial clinics required to deal with the 2 year follow up of cases. With a substantial number of non English speaking individuals involved in the outbreak, interpreter services have been required throughout the outbreak and for the follow up clinics (Pollock et al., 2007). The total financial burden of this outbreak is likely to be considerable when taking into account the time spent in managing the out break by representatives from the significant number of agencies in the Outbreak Control Team, provision of interpreters, chronic follow up by the NHS, decreased production for the company and sickness absence for individual workers.

This outbreak highlights the significance of taking into consideration the type of industry in occupational out breaks. Whilst Q fever was always high on the list of differential diagnoses in the initial days of the outbreak, other possible causes had to be considered and ruled out such as legionella. It also reinforces the need for investiga tions performed in community acquired pneumonia to be guided by the severity of the pneumonia, epidemiological risk factors and response to treatment (British Thoracic Society Standards of Care Committee, 2001). There is an occupational risk to all who work near livestock and for those who process some animal by products. In Northern Ireland, $C$ burnetii antibody seropositivity in a sample from the general population of 1264 year olds was $12.8 \%$, whereas in farmers it was significantly higher at 48.8\% (McCaughey et al., 2008).

A live, whole cell vaccine ( $Q$ Vax) has been licensed for use in Australia since 1989 (Marmion et al., 1990), and acellular vaccines also exist (Camacho et al., 2000; Waag et al., 2002). Vaccine efficacy has been estimated to be between 83 and $100 \%$ in non randomized retrospective cohort studies (Chiu and Durrheim, 2007). Immunization against Q fever is recommended in Australia for abattoir workers, and others exposed to cattle, sheep, goats and kangaroos or their products (Australian Government, 2003), and a national vaccination register is kept. Vaccine use in meat industry workers in Australian abattoirs has been estimated to cost $\$ 6294$ per quality adjusted life year gained (Kermode et al., 2003). However, vaccine use is currently not licensed in the United Kingdom.

The potential economic and clinical health burden of infection with $C$. burnetii has been slow to gain the atten tion that it merits. It is important that information from $\mathrm{Q}$ fever outbreaks is used not only in the direct manage ment of the outbreak but also to add to the evidence base, to guide and inform national policy and raise public awareness about the disease.

\section{Acknowledgements}

We would like to thank the members of the Outbreak Control Team, NHS Forth Valley public health depart ment and the Health and Safety Executive for facilitating the epidemiological investigation; and NHS Forth Valley 
Microbiology Laboratory and the West of Scotland Regional Virology Centre for serological analysis and interpretation; and Dominic Mellor for helpful comments.

\section{Financial Support}

None.

\section{Conflict of Interest}

None.

\section{Biographical Sketch}

Dr Wilson is a public health physician and paediatrician with an interest in the epidemiology of respiratory disease and surveillance systems.

\section{References}

Australian Government, 2003: The Australian Immunisation Handbook, 8th edn. National Health and Medical Research Council, Commonwealth of Australia Department of Health and Ageing, Canberra.

British Thoracic Society Standards of Care Committee, 2001: BTS guidelines for the management of community acquired pneumonia in adults. Thorax 56(Suppl. 4), IV1 IV64.

Camacho, M. T., I. Outschoorn, E. Kovácová, and A. Téllez, 2000: Distribution of immunoglobulin G (IgG) and A(IgA) subclasses following $\mathrm{Q}$ fever vaccination with soluble phase 1 Coxiella burnetii extract. Vaccine 18, 17731777.

Chiu, C. K., and D. N. Durrheim, 2007: A review of the efficacy of human Q fever vaccine registered in Australia. N. S. W. Public Health Bull. 18, 133136.

Cutler, S. J., G. A. Paiba, J. Howells, and K. L. Morgan, 2002: Q fever a forgotten disease? Lancet Infect Dis. 2, 717718.

Derrick, E. H., 1937: "Q" fever, a new fever entity: clinical fea tures, diagnosis and laboratory investigation. Med. J. Aust. 2, 281299.

Fenollar, F., P. E. Fournier, M. P. Carrieri, G. Habib, T. Mes sana, and D. Raoult, 2001: Risks factors and prevention of Q fever endocarditis. Clin. Infect. Dis. 33, 312316.

Hawker, J. L., J. G. Ayres, I. Blair, M. R. Evans, D. L. Smith, E. G. Smith, P. S. Burge, M. J. Carpenter, E. O. Caul, B. Coupland, U. Desselberger, I. D. Farrell, P. J. Saunders, and M. J. Wood, 1998: A large outbreak of Q fever in the West Midlands: windborne spread into a metropolitan area? Commun. Dis. Public Health 1, 180187.

Health Protection Agency, 20 July 2007; Q Fever Cluster in Chel tenham. Health Protection Agency, London. Health Protec tion Report, Vol 1, No 29.
Kermode, M., K. Yong, S. Hurley, and B. Marmion, 2003: An economic evaluation of increased uptake in $\mathrm{Q}$ fever vaccina tion among meat and agricultural workers following imple mentation of the National Q Fever Management Program. Aust. N. Z. J. Public Health 27, 390398.

Marmion, B. P., R. A. Ormsbee, M. Kyrkou, J. Wright, D. A. Worswick, A. A. Izzo, A. Esterman, B. Feery, and R. A. Shapiro, 1990: Vaccine prophylaxis of abattoir associated Q fever: eight years' experience in Australian abattoirs. Epidem iol. Infect. 104, 275287.

Maurin, M., and D. Raoult, 1999: Q fever. Clin. Microbiol. Rev. 12, 518553.

McCaughey, C., J. McKenna, C. McKenna, P. V. Coyle, H. J. O’Neill, D. E. Wyatt, B. Smyth, and L. J. Murray, 2008: Human seroprevalence to Coxiella burnetii (Q fever) in Northern Ireland. Zoonoses Public Health 55, 189194.

Pollock, K. G., D. J. Mellor, L. M. Browning, L. Wilson, and Donaghy. M, 2007: Q fever in migrant workers, Scotland. Emerging Infect. Dis. 13, 19631964.

Raoult, D., and T. Marrie, 1995: Q fever. Clin. Infect. Dis. 20, 489496.

Raoult, D., F. Fenollar, and A. Stein, 2002: Q fever during pregnancy; diagnosis, treatment and follow up. Arch. Intern. Med. 162, 701704 .

Shapiro, R. A., V. Siskind, F. D. Schofield, N. Stallman, D. A. Worswick, and B. P. Marmion, 1990: A randomized, con trolled, double blind, cross over, clinical trial of Q fever vac cine in selected Queensland abattoirs. Epidemiol. Infect. 104, 267273.

Smith, D. L., J. G. Ayres, I. Blair, P. S. Burge, M. J. Carpenter, E. O. Caul, B. Coupland, U. Desselberger, M. Evans, I. D. Farrell, J. I. Hawker, E. G. Smith, and M. J. Wood, 1993: A large Q fever outbreak in the West Mid lands: clinical aspects. Respir. Med. 87, 509516.

Thomas, D. R., L. Treweek, R. L. Salmon, S. M. Kench, T. J. Coleman, D. Meadows, P. Morgan Capner, and E. O. Caul, 1995: The risk of acquiring Q fever on farms: a seroepidemi ological study. Occup. Environ. Med. 52, 644647.

Van Woerden, H. C., B. W. Mason, L. K. Nehaul, R. Smith, R. L. Salmon, B. Healy, M. Valappil, D. Westmoreland, S. de Martin, M. R. Evans, G. Lloyd, M. Hamilton Kirkwood, and N. S. Williams, 2004: Q fever outbreak in industrial setting. Emerging Infect. Dis. 10, 12821289.

Waag, D. M., M. J. England, R. F. Tammariello, W. R. Byrne, P. Gibbs, C. M. Banfield, and M. L. Pitt, 2002: Comparative efficacy and immunogenicity of Q fever chloroform:metha nol residue (CMR) vaccine and phase 1 cellular ( $Q$ Vax) vaccines in cynomolgus monkeys challenged by aerosol. Vaccine 20, 26232634.

Wildman, M. J., E. G. Smith, J. Groves, J. M. Beattie, E. O. Caul, and J. G. Ayres, 2002: Chronic fatigue following infec tion by Coxiella burnetii ( $\mathrm{Q}$ fever): ten year follow up of the 1989 UK outbreak cohort. QJM 95, 527538. 